\title{
Human Resource Policies and Practices: Evaluating and Reviewing the Contemporary Recruiting Process
}

\author{
Eluojor A. Onnekikami \\ Lecturer of Management \& Human Resources \\ Department of Business and Economics \\ California State University \\ Los Angeles, CA, United States \\ Email: eonneki@cal.state.edu \\ Paul C. Okpala \\ Assistant Professor, Department of Health Sciences \\ California State University, San Bernardino CA
}

Received: February 22, 2016 Accepted: February 29, 2016 Published: March 28, 2016

doi:10.5296/ijhrs.v6i1.9113 URL: http://dx.doi.org/10.5296/ijhrs.v6i1.9113

\begin{abstract}
The main purpose of this article is to have an overview of Human Resource (HR) policies and practices, especially as it relates to the contemporary and evolutional process of talent recruitment. The article encompasses an overview of HR general policies and practices including the selection process, applications, background checks, substantive selection, interviews; the contingent selection process and what to do after the job offer. In short, organizations are decreasing the use of external recruiting companies or agencies and are now often counting on their own HR professionals for talent search. For instance, internal HR professionals are now utilizing different online tools such as job boards, LinkedIn and social media to discover ideal job candidates and these popular platforms have proven invaluable in the modern recruiting process.
\end{abstract}

Keywords: Application forms, Background checks, Human resources, Selection process, Recruiting 


\section{Introduction}

One of the most paramount functions of the Human Resources Department of any Organization is the hiring of the right individuals to fill vacant positions in the company. This function has not necessarily changed, but the methods of seeking and hiring the right individuals in contemporary organizations tend to have changed by the use of modern technologies [10]. The age-old question of how to find the right individual, or hire a perfect fit, remains the quintessential goal of all Human Resources (HR) departments. When hiring managers fail to hire the right individual, or hire a perfect fit, employee satisfaction and performance often suffers $[2,13]$. As the number of applications for a single position continues to increase, it is imperative that the HR department and hiring managers develop an effective methodology for screening and eventually selecting the most qualified person irrespective of whether the traditional or contemporary recruiting methodology is utilized [1, 4]. Thus, it is no longer enough that a candidate has all the right qualifications. It is also necessary that the person will fit the corporate culture. Otherwise, he or she may not feel at home in the environment. For instance, not everyone is suited to be in retail industry because it sometimes requires long hours and even staying well into the night during inventory periods. People who do not like this environment would have to be weeded out to avoid wasting time on both sides.

The main purpose of this article is to review organization's human resource (HR) policies and practices especially as it relates to contemporary ways of the recruiting process. The general overall HR policies and practices such as selection process, applications, background checks, substantive selection, interviews; the contingent selection process and what to do after the job offer are also reviewed [3,10]. Organizations are decreasing the use of outside recruiting companies or agencies and are now often counting on their own HR professionals for talent search. Organizations HR professionals are now utilizing different online tools such as job boards, LinkedIn and social media to mention but a few to search for the right talents $[5,6,7]$.

It is important to note that recruitment of candidates is still been done through traditional mediums, such as advertising through newspapers or going to colleges to recruit graduating students, or through the use of the internet to post job placements. However as previously stated, staffing is not merely finding the candidates with the right qualifications but also ensure that the chosen applicants will fit the organizational way of doing things. Today's platforms however, tend to yield an exponential number of job applicants. Some companies are even pioneering a unique methodology such as online programming contests, which parade as games, in order to identify and engage potential employees with the best skill sets that might be convinced to apply for their vacant positions $[7,8,10,12]$.

\section{The Selection Process}

Both the traditional and modern recruiting process often begins with organizations encouraging applicants to fill out job applications [8,10,11]. Application forms and resumes are often the initial selection devices. A thorough background check is also very important in the selection process. Some organizations use background check as a contingent or initial selection device. In order words, a company might check on an applicant's background right 
way, or others might use it after an employee has been partially hired contingent upon the background checking out as stated in the application [6,9]. Some organizations are known for eliminating background checks altogether and instead rely on hiring family and friends. To some scholars, this aforementioned method is controversial because it often hurts workplace diversity, which study has indicated could increase organizational performance and profitability $[9,11,12]$. Some companies on the other hand, often aim to recruit potential employees who might not pass background checks such as those with criminal backgrounds because they want to offer them a second chance. Some organizations that have engaged in this hiring practice often report that such employees have later become an important and valuable member of their workforce [10].

\section{Application Forms}

The information submitted in application forms by itself is often not necessarily the best predictor of performance. Nonetheless, it could be a great initial screen. For example, it will not make much sense for a hiring manager to spend time interviewing an applicant for a position as a special education teacher if the potential applicant does not have the stated requirements in the job announcements such as proper credentials, certification and experiences. Many of today's companies encourage applicants to apply for their vacant position online. It often takes a short time to fill out such forms and could be forwarded fast to the hiring decision maker $[10,11]$. Additionally, most companies have employment and job requisition pages on their websites where potential employees can search for available positions in their organizations. Most applicants today are more likely to upload or email their resume rather than mailing it out the traditional way via the local post office $[1,9]$.

Some companies are now asking for photos when applicants submit their electronic application and then scanning the attach photo with facial recognition to match the potential applicant with their applicant social security number, home address, criminal record and credit reports $[10,11]$. However, some scholars argued that even though it might seem to be a good practice on the surface, it could become a big legal issue in the future for organizations, because applicants could easily claim discrimination based on their pictures. They may claim that because they belong to a particular minority group, then that is reason they were not interviewed or hired for the position. Human resource managers must also be careful about the questions they ask their potential employees. Questions relating to gender, race and nation of origin are prohibited by law $[9,11,12]$.

To help with the overwhelming number of electronic applications that human resources department receive, it has become common for the hiring department to use some sort of software to prescreen applicants based on keyword that matches submitted applications and the qualifications that are needed for the job [8,9]. The goal of such software is to seek and screen unacceptable applicants. So it is important for applicants to adhere and incorporate all keywords that accurately describe their experiences, which will at least give them the opportunity to be called for an interview $[3,4]$. 


\section{Background Checks of Applicants}

Research indicates that $80 \%$ of HR departments conduct employment and reference checks provided by applicants [10]. The reason for these checks is that organizations want to know how applicants did in their former jobs and if the former company will recommend the applicant to be hired. However, most former employers do not necessarily provide useful information because of the fear of litigation if the former employee felt that something inaccurate was said to the potential new employer. According to some scholars, most concerns by former employers are often unfounded as long as the information provided are documented events [7, 8]. Another form of background check includes letters of recommendations. These letters are not necessarily useful to hiring managers because applicants most often select an individual they know that will only say positive things about them. Consequently most hiring departments tend to ignore them completely $[8,9]$.

Some HR departments now utilize social network sites such as Facebook and LinkedIn as tools for conducting background checks. A study found that independent reviewers viewing applicant's Facebook profiles were able to accurately determine or predict applicants' agreeability, conscientiousness and job intelligence, which later translated into job performance scores as recorded by the line manager or supervisors. The legality of the aforementioned practice could be a major concern, nevertheless, the fact remains that most employers use electronic search engines to see whether potential employees have any history in the internet that might make them a potential liability to their organization $[7,9]$.

It is also important to note that some hiring departments now also check applicant credit histories. The checking of credit history was initially used by banks to check on their job applicants, but non-banking organizations are now also checking their job applicant's credit history $[1,2,10]$. A study has shown that organization citizenship behaviour, in some situations, task performance, and conscientiousness could be related to an applicant's credit scores $[12,13]$. However, a study also indicated, that minority status tends to frequently adversely relate to individual credit scores, while on the other hand, educational attainment and age tend to be positively related. As a result of this potential discrimination concern, and the invasive nature of using credit checks, HR departments must evaluate their recruiting process to ascertain if checking of applicants credit report is necessary [10].

It is important to note that the United States Equal Employment Opportunity Commission (EEOC) states that job candidates can not be denied job employment based on findings of any background checks, and some experts in the field are of the opinion that the results tend to be inaccurate $[10,13]$. Legally, a candidate's criminal history can only be used for rejection, if such violation is job-related. For example, an applicant that has a history of embezzlement could be rejected on a finance job but not necessary as a mechanic. Based on the aforementioned, it might appear that there is no compelling need for organizations to do a background check. However, failure to conduct a background check might come with a huge legal cost. For example, a nursing home in Texas did not conduct a criminal background check on an employee that was a registered sex offender, who later went and molested one of the clients. The client's family was awarded $\$ 1.1 \mathrm{~m}$ by the jury as the nursing 
home was found to be negligent for not conducting the criminal background check before the employee was hired [10].

\section{Substantive Selection Process}

Upon completion of the initial screen of a candidate, often comes the heart of the substantive selection process such as written tests and interviews. The traditional written test is called the paper and pencil and was used between 1960s and 1980s in the United States [10, 13]. These traditional tests were often characterized as being discriminatory, and many companies have not shown that they were job-related. However, some of today's organizations have moved these tests online and are using them on their job applicants [1,5]. Most of today's company's recognizes that a valid test could help the organization predict which of the prospective candidates will be most successful in their role. A typical written test often includes; cognitive ability tests; interest inventory tests; personality tests and integrity tests, and have been found to be useful in determining the probability of how a candidate may fare on the job $[6,7]$.

Moreover, the use of personality tests as another applicant filter has been on the rise in recent years. These tests are often inexpensive and are easy to administer. One of the major traits measured in a personality test is conscientiousness. Research has shown that individuals that are conscientious tend to be dependable, motivated, have a positive attitude and are often persistent. However, it is also a known fact that applicants often fake responses to these questions. To address this concern, HR departments are encouraged to seek employment references about candidates' personality as part of the selective procedure or process $[7,8]$.

\section{Interviews}

The interview can be very nerve-wracking experience for most job applicants but is considered by most experts as the best selection process that companies use to differentiate applicants [4,11]. Interviews play an important role in determining whether an organization and an applicant will make a perfect match. The job interview often serves as a two-way conversation in which the interviewer and applicant exchange information. The organization has the opportunity to learn more about their potential employee background, and provide the applicant with in-depth information about the organization and give a detail job description and the expectations of the company [9,10,13]. The interviewer utilizes the process to determine if the applicant will be a good fit for the position. During the interview process, the applicant also has the chance to ask valuable questions to enable him/her to gain additional insights regarding job expectations and if the job will be a good fit for him or her $[6,8]$.

Study have shown that without structure, interviewers might favor applicants that share behaviors they like, and allows the order in which job candidates were interviewed to influence their decisions [10]. To reduce such aforementioned biases and improve the validity of held interviews, hiring managers are encouraged to adopt a standardized set of job-related questions, a standardized rating of all applicants' qualifications, and a methodology of recording all information provided by each applicant. Interviewers should be trained to focus 
on the specifics of the job description and anticipated performance during the interviews. Additionally, experts are of the perspective that the interview process or effectiveness is improved when hiring managers utilize behavioral-structured interviews, because such assessments tend to be less influenced by interviewer biases [8,13]. Utilizing the behavioral-structured interviews often require applicants to describe how they have or will handle specific problematic situation, and is based on presumption that an individual's past behavior tend to offer the best predictor of a future behavior $[11,12,13]$

\section{Contingent Selection Process}

Upon the completion of previously described substantive selection process, the job applicant is almost ready to be hired, contingent upon various final checks such as drug tests. For example, most retail stores often make tentative job offers to an applicant that is contingent on them passing their drug test. Drug testing of job applicants is controversial [10]. Many job applicants are of the opinion that testing without a reasonable suspicion is an invasion of their privacy and not job-related. They believe that one's lifestyle choice should not be relevant to the job. However, most organizations often counter that drug abuse and use are often very costly, not only financially but in terms of the safety of other employees within the organization. It should be noted that the U.S. Supreme Court has concluded that drug tests are at best, a "minimally invasive" selection process that as a rule, does not violate peoples' rights [10].

\section{Job Offer}

The final step in the selection process is the job offer. After the great deal of energy and work put in the selection process, the final goal is hopefully a good fit for both the candidate and the organization. It is paramount for the candidate to maintain the drive and focus that sustained him/her throughout the process in order to decide if the job is an ideal fit $[5,6]$.

When an offer is made, it often comes via email and includes, the job title, the salary being offered, terms of employment, benefits being offered and a start date. It is important and recommended that when a candidate receives an offer letter, they should acknowledge the offer and send a thank you letter to the company's representative that signed the letter and request a few days to consider the offer if necessary. It should be a period for the candidate to evaluate his/her priorities as it relates to the offer. Both personal and organizational factors should be evaluated by the candidate. Personal factors such as whether the job meets one's goal and priorities; if the offer is accepted, will the candidate be able to meet family commitments and responsibilities; and does the benefits package meets his/her needs to mention but a few. Organizational factors to be considered includes but not limited to; is the organization's mission and values a close to perfect fit; do the current colleagues appear to be individual he/she can trust and work with; is the work place compatible to his/her strengths; and has the company adequately outlined one's responsibilities, reporting line, work conditions and schedule?

Once a candidate has decided to accept or not to accept a job offer, it is important to contact the organization via email or telephone. If the candidate accepts the offer, there is often a box 
in the offer letter to indicate acceptance or denial of the offer.[4, 7]

If a candidate declines an offer, it important for the candidate to convey his/her gratitude to the organization for the job offer and the consideration that was shown throughout the process. The applicant should also express his/her hope for the company's continued success. The candidate should also state that it was a difficult decision for him/her and commend the organization for the paramount work they are doing for the community $[11,12]$.

\section{Conclusion}

Human Resources Department of Organizations should endeavor to hire the right individuals to fill vacant positions in their companies. This function has not necessarily changed, but contemporary methods of seeking and hiring the right individuals has increased the number of applicants by the use of modern technologies. When hiring managers fail to hire the right individual, or hire a perfect fit, employee satisfaction and performance often suffers. As the number of applications for a single position continues to increase, it is imperative that the HR department and hiring managers develop an effective methodology for screening and eventually selecting the most qualified person irrespective of whether the traditional or contemporary recruiting methodology is utilized.

\section{References}

1. Altmann, P. (2015). Managing Human Resources and Technology innovation: The impact of process and outcome uncertainties. International Journal of Innovation, 7(2), p91-1066.

2. Alisheva, D.M., Tomilova, N., Mushaseva, G., Mukhametzhanova, B. \& Naumova, A.V (2014). The role of information technology in improving human resources management system of the company. European Researcher, 70(3-1), 478-483.

3. Breslin, M.M. (2012). Can You Handle Rejection? Workforce Management, p32-36.

4. Charleston, L.J. (2013). Using human resource software technology to mitigate glass ceiling effects in higher education: Interdisciplinary applications for managing diversity. New Directions for Institutional Research, 159, 63-73.

5. Cloud, N.C (2014). Human resources training: Where do we go from here? Army Sustainment, 48-52.

6. Hunter, J.E. (1986). Cognitive ability, Cognitive aptitude, Job knowledge, and Job performance. Journal of Vocational Behaviour, 29(3), 340-362.

7. Konig, C.J., Merz, A.S \& Trauffer (2012). What is in applicant mind when they fill out personality tests? Insights from a qualitative study. International Journal of Selection and Assessment, p442-450.

8. Nielsen, K. \& Pedersen, L.M (2014). What do social processes mean for quality human resource practice? Nordic Journal of Working Life Studies, 4(2), 21-45. 
9. Ozien, M.K.(2014). The Recent Trend in a Human Resource Management Journal: A Keyword Analysis. European Researcher, 79(7), 1367-1375.

10. Robbins, S.P., \& Judge, T.A (2015). Organizational Behavior $\left(16^{\text {th }}\right.$ ed), Pearson Publications, New Jersey ISBN 978-0-13-350764-5.

11. Shien, P.H. (2014). Effects of Human Resource Flexibility strategy on work attitude towards micro-enterprises on Taiwan. Pakistan Journal of Statistics, 30(6), 1289-1300.

12. Trebbkem T, M., Heyworth, N., Clarke, N., Powell, T., \& Hockey, P.M (2014). Managing hospital doctors and their practice: what can we learn about human resource management form non-health care organizations? BMC Health Services Research, 14(1), 566-588.

13. Vosburgh, R.M. (2014). A Chief human resource officer (CHRO) and practitioner's view of OD. OD Practitioner, 46(4), 62-64. 